\title{
A snapshot of nephron-sparing surgery in Italy: A prospective, multicenter report on clinical and perioperative outcomes (the RECORd 1 project)
}

\author{
R. Schiavina ${ }^{\mathrm{a}, *}$, A. Mari ${ }^{\mathrm{b}}$, A. Antonelli ${ }^{\mathrm{c}}$, R. Bertolo ${ }^{\mathrm{d}}, \mathrm{G}$. Bianchi ${ }^{\mathrm{e}}$, \\ M. Borghesi ${ }^{a, k}$, E. Brunocilla ${ }^{a}$, C. Fiori ${ }^{\mathrm{d}}$, N. Longo ${ }^{\mathrm{f}}$, \\ G. Martorana ${ }^{\mathrm{a}}$, V. Mirone ${ }^{\mathrm{f}}$, G. Morgia ${ }^{\mathrm{g}}$, G. Novara ${ }^{\text {h}}$, F. Porpiglia ${ }^{\mathrm{d}}$, \\ B. Rovereto ${ }^{\mathrm{i}}$, S. Serni ${ }^{\mathrm{b}}$, C. Simeone ${ }^{\mathrm{c}}$, M. Sodano ${ }^{\mathrm{c}}$, C. Terrone ${ }^{\mathrm{j}}$, \\ M. Carini ${ }^{\mathrm{b}}$, A. Minervini ${ }^{\mathrm{b}}$ \\ a Dipartimento di Urologia, Università di Bologna, Ospedale S. Orsola-Malpighi, Bologna, Italy \\ ${ }^{\mathrm{b}}$ Clinica Urologica I, AOUC, Università di Firenze, Italy \\ ${ }^{c}$ Unità Operativa di Urologia Dipartimento di NefroUrologia, Azienda AO Spedali Civili di Brescia, Italy \\ ${ }^{\mathrm{d}}$ Divisione di Urologia, Università di Torino, Ospedale San Luigi Gonzaga, Orbassano, Torino, Italy \\ ${ }^{\mathrm{e}}$ Policlinico di Modena, Clinica Urologica, Università di Modena, Italy \\ ${ }^{\mathrm{f}}$ Policlinico Federico II, Università di Napoli, Italy \\ ${ }^{\mathrm{g}}$ Luna Foundation, Italy \\ ${ }^{\mathrm{h}}$ Clinica Urologica, Università di Padova, Padova, Italy \\ ${ }^{\mathrm{i}}$ I.R.C.C.S. Policlinico San Matteo - Struttura Di Urologia, Pavia, Italy \\ ${ }^{\mathrm{j}}$ Dipartimento di Urologia, Azienda Ospedaliera Maggiore Della Carità, Novara, Italy \\ ${ }^{\mathrm{k}}$ Dipartimento in Scienze Mediche e Chirurgiche (DIMEC), dottorato in Scienze Cardio Nefro Toraciche, Alma \\ Mater Studiourum, Universita di Bologna, Bologna, Italy
}

Accepted 11 December 2014

Available online 27 December 2014

\begin{abstract}
Introduction: Nephron-sparing surgery (NSS) has become the standard of care for the surgical management of small and clinically localized renal cell carcinoma (RCC). The conservative management of those RCCs is increasing over time. Aim of this study was to report a snapshot of the clinical, perioperative and oncological results after NSS for RCC in Italy.

Material and methods: We evaluated all patients who underwent conservative surgical treatment for renal tumours between January 2009 and December 2012 at 19 urological Italian Centers (RECORd project). Perioperative, radiological and histopathological data were recorded. Surgical eras (2009 vs 2012 and year periods 2009-2010 vs 2011-2012) were compared.

Results: Globally, 983 patients were evaluated. More recently, patients undergoing NSS were found to be significantly younger ( $\mathrm{p}=0.05$ ) than those surgically treated in the first study period, with a significantly higher rate of NSS with relative and imperative indication $(\mathrm{p}<0.001)$. More recently, a higher percentage of procedures for cT1b or cT2 renal tumours was observed $(\mathrm{p}=0.02)$. Utilization rate of open partial nephrectomy (OPN) constantly decreased during years, laparoscopic partial nephrectomy (LPN) remained almost constant while robot-assisted partial nephrectomy (RAPN) increased. The rate of clampless NSS constantly increased over time. The use of at least one haemostatic agent has been significantly more adopted in the most recent surgical era $(\mathrm{p}<0.001)$.

Conclusions: The utilization rate of NSS in Italy is increasing, even in elective and more complex cases. RAPN has been progressively adopted, as well as the intraoperative utilization of haemostatic agents and the rate of clampless procedures.
\end{abstract}

(C) 2014 Elsevier Ltd. All rights reserved.

Keywords: Renal cell carcinoma; Partial nephrectomy; Nephron-sparing surgery; Minimally invasive techniques; Outcomes

* Corresponding author. Department of Urology, University of Bologna, S. Orsola-Malpighi Hospital, Palagi 9, 40134, Bologna, Italy. Tel.: +39 3494447896; fax: +390516362747.

E-mail address: rschiavina@yahoo.it (R. Schiavina). 


\section{Introduction}

Based on the GLOBOCAN estimates, over 143.300 new renal cell carcinoma (RCC) between both genders have been diagnosed in 2012, accounting for approximately 74.900 deaths in the developed countries. ${ }^{1}$ The increased diagnosis of RCC led to a concurrent rise in the utilization of surgical procedures and to an augmented interest in the various techniques of nephron-sparing surgery (NSS) over radical nephrectomy (RN). NSS demonstrated to offer cancer specific free-survival rates comparable to radical nephrectomy (RN), but with lower risk of surgically induced chronic kidney disease (CKD), cardiovascular events and metabolic sequelae. ${ }^{2,3}$ For this reason, European guidelines has recently accepted as standard of care NSS for the treatment of $\leq 4 \mathrm{~cm}$ renal tumours and recommended a conservative surgery for 4-7 cm (cT1b) renal masses whenever technically feasible. ${ }^{4}$ However, the surgical treatment of renal tumours still represents an area of active clinical research and controversies still exist, which includes the therapeutic strategy (NSS, RN), the technique to perform NSS (partial nephrectomy, tumour enucleation), the approach for NSS (open, laparoscopic, robotic) and whether or not to clamp the renal pedicle during NSS. Aim of the present study was to report data of a large cohort of patients undergoing NSS for renal tumours between January 2009 and December 2012 among Italian Centres, and to offer a "real-life" description of the clinical, perioperative and pathological results after NSS for renal tumours together with a comparison among the different surgical periods.

\section{Material and methods}

The Italian Registry of Conservative Renal Surgery (RECORd Project) is a 4-Year prospective observational multicenter study promoted by the Leading Urological No profit foundation Advanced research (LUNA) of the Società Italiana di Urologia (SIU). The RECORd project includes all patients who underwent conservative surgical treatment for radiologically diagnosed renal cell carcinoma (RCC) between January 2009 and December 2012 at 19 urological Italian Centres, upon the approval of the study protocol by the local ethical committee and patients' acceptance of the written informed consent. Overall, information about 1055 patients were collected. An online database was generated and it comprises 5 main folders: 1) Anthropometric and Preoperative data; 2) Imaging, Indications and Comorbidities; 3) Intraoperative Data; 4) Postoperative Data; 5) Histopathological Analysis. All data were centrally recorded on a data server. All preoperative anthropometric characteristics were collected (gender, age, BMI). Surgical indications were defined as elective (localized unilateral RCC with healthy contralateral kidney), relative (localized unilateral RCC with the coexistence of comorbidities such as diabetes, hypertension or lithiasis that could potentially affect kidney function in the future) and absolute (bilateral tumours, multiple tumours, moderate to severe CKD or in case of neoplasia involving an anatomically or functionally solitary kidney). Performance status was assigned according to the ECOG criteria. ${ }^{5}$ Mode of presentation of the tumour was defined according to the Patard classification. ${ }^{6}$ In all patients clinical workup included at least abdominal computed tomography (CT) scans and chest X-rays. Chest and brain CT scans were obtained only when indicated by signs and symptoms. Tumours were classified according to their location on the longitudinal plane (upper pole, middle part, and lower pole) and on the transverse plane (anterior surface, posterior surface, lateral margin, medial margin, peri-hilar) of the kidney. According to the degree of depth into the kidney, each tumour was also classified into three growth pattern categories: 1) prevalently $(\geq 50 \%)$ exophytic, 2) prevalently endophytic ( $<50 \%$ exophytic), and 3 ) entirely endophytic. Analysing full dataset of 1055 cases, centres were divided in low- and high-volume according to the threshold of 50 interventions of NSS per year. All intraoperative data including surgical approach and technique, the decision whether or not to clamp the renal vessels, type of ischaemia, ischaemia time, intraoperative blood loss and operative time were recorded. The minimally invasive (video laparoscopic or robot assisted) and open approaches as well as the surgical technique, performed in the form of standard PN and simple enucleation (SE), were adopted according to the centres' and surgeons' preference. Standard PN has been defined as the excision of the tumour and of a minimal margin of healthy peritumoral renal parenchyma. ${ }^{7} \mathrm{SE}$ has been defined as the blunt tumour excision without removing a visible rim of parenchymal tissue around the pseudocapsule. ${ }^{7}$ All surgical specimens were processed according to standard pathological procedures at each institution by experienced uropathologists. For surgical margins evaluation the specimens were fixed in $10 \%$ buffered formalin, and grossly analysed. The size, the colour, the gross aspect (solid to cystic) were recorded and the surgical margin was marked with ink. After tumour dissection, samplings were performed in order to obtain tissue blocks where tumour, renal parenchyma, and surgical edges were comprised and further blocks where tumour, renal capsule, and peritumoral fat were enclosed. The margin was considered positive when tumour tissue was marked with ink. The margin was considered negative when no-neoplastic renal tissue was observed between tumour tissue and the line of ink. Tumours were pathologically staged according to the American Joint Committee on Cancer TNM classification. ${ }^{8}$

\section{Statistical analysis}

Continuous variables were reported as mean (SD) or as median and IQR, as appropriate. The Student $\mathrm{t}$ test and the Mann-Whitney $U$ test were used to compare continuous variables and the Pearson's chi square test was used to 
compare categorical variables. Surgical eras (2009 vs 2012 and year periods 2009-2010 vs 2011-2012) were compared regarding clinical and surgical variables. Statistical significance in this study was set as $p \leq 0.05$. All reported $p$ values are two-sided. Analyses were performed with SPSS version 20.0 (SPSS Inc, Chicago, IL, USA).

\section{Results}

A total of 1055 patients from 19 Italian Centers were included in the study. After exclusion of 72 patients with incomplete perioperative data, the remaining 983 patients were evaluated for the final analyses. Overall, $64.8 \%$ of patients were male, and the majority of them were fit and fully active at the time of surgery (ECOG performance status $=0: 69.1 \%)$. The most relevant clinical and demographic results, together with a comparison among the different surgical eras are reported in Table 1. In the most recent years, patients undergoing NSS were found to be significantly younger $(\mathrm{p}=0.05)$, with a significantly higher percentage of ECOG $0(p=0.002)$ and asymptomatic presentation $(p<0.0001)$ than those surgically treated in the first study period. In all the centres, most of the PN were performed with elective indication, even if a significantly higher rate of NSS with relative and imperative indication was observed in the most recent years $(\mathrm{p}<0.001$, Table 1). Notably, patients undergoing partial nephrectomy were diagnosed with slightly larger renal tumours over time $(\mathrm{p}=0.04)$ and, therefore, a higher percentage of procedures for cT1b renal masses was observed in the most recent era $(\mathrm{p}=0.02)$. Intraoperative data are detailed in Table 2.

Overall, enucleoresection was the most widely adopted technique over time (59.6\% of cases), but a slightly higher rate of SE was observed in 2012 compared to 2009 $(\mathrm{p}=0.04)$. Globally, OPN was adopted in almost two third of cases $(563 / 983 ; 57.2 \%)$ while the laparoscopic approach in $30.8 \%$ of cases (302/983); since 2011, robot-assisted partial nephrectomy (RAPN) has been included in the multiinstitutional database, comprehensively representing $12 \%$ of the total cases (118/983, Table 2). Notably, we observed a significant and persistent increase in the utilization of RAPN in the last two years, a constant decrease in the use of the OPN over all the period and a slight reduction of laparoscopic NSS rate during the last two years (Fig. 1). When stratifying the data according to the tumour's clinical stage, open and laparoscopic approaches constantly decrease from 2008 to 2012 for the treatment of cT1a renal tumours. In 2012 RAPN represents the most performed treatment for cT1a (Fig. 2a). Conversely, when considering larger tumours (cT1b), OPN constantly decreased over the study period, laparoscopic partial nephrectomy (LPN) remained approximately constant and RAPN increased. In 2012 LPN and RAPN together represent $61.9 \%$ of interventions for cT1b tumours (Fig. 2b). Overall, $36.3 \%$ of patients (357/983) underwent clampless NSS and its rate constantly increased over time, from $33 \%$ in 2009 to $42.4 \%$ in 2012 . When separately analysing each approach, clampless procedures increased from $29.0 \%$

Table 1

Demographic, clinical and pathological results of the entire cohort of patients, stratified by surgical era.

\begin{tabular}{|c|c|c|c|c|c|c|c|c|c|c|c|}
\hline \multicolumn{2}{|l|}{ RECORd1 } & \multicolumn{8}{|c|}{ Single year evaluation } & \multicolumn{2}{|l|}{$\mathrm{p}$} \\
\hline & & 2009 & & 2010 & & 2011 & & 2012 & & 2009 vs 2012 & $2009 / 10$ vs $2011 / 12$ \\
\hline \multirow[t]{2}{*}{ Gender, n. (\%) } & Male & 213 & $68.3 \%$ & 176 & $64.9 \%$ & 142 & $63.7 \%$ & 106 & $59.9 \%$ & 0.06 & 0.13 \\
\hline & Female & 99 & $31.7 \%$ & 95 & $35.1 \%$ & 81 & $36.3 \%$ & 71 & $40.1 \%$ & & \\
\hline \multicolumn{2}{|l|}{ Age, mean (SD) } & 64.2 & 11.5 & 62.5 & 12.9 & 60.5 & 14.8 & 61.0 & 13.6 & 0.05 & 0.05 \\
\hline \multicolumn{2}{|l|}{ BMI, median (IQR) } & 26.1 & $24.3-28.4$ & 25.9 & $23.6-27.8$ & 25.8 & $23.9-27.7$ & 26.4 & $24.2-29.4$ & 0.75 & 0.69 \\
\hline \multirow{3}{*}{$\begin{array}{l}\text { Symptomatologic } \\
\text { class, n. } \%\end{array}$} & Asymptomatic & 263 & $84.3 \%$ & 225 & $83.0 \%$ & 203 & $91.0 \%$ & 167 & $94.4 \%$ & $<0.0001$ & 0.002 \\
\hline & Local sympt. & 38 & $12.2 \%$ & 38 & $14.0 \%$ & 18 & $8.1 \%$ & 10 & $5.6 \%$ & & \\
\hline & Systemic sympt. & 11 & $3.5 \%$ & 8 & $3.0 \%$ & 2 & $0.9 \%$ & 0 & $0.0 \%$ & & \\
\hline \multirow[t]{3}{*}{ Indication, n. (\%) } & Elective & 256 & $82.1 \%$ & 221 & $81.5 \%$ & 170 & $76.2 \%$ & 133 & $75.1 \%$ & $<0.0001$ & $<0.0001$ \\
\hline & Relative & 22 & $7.1 \%$ & 27 & $10.0 \%$ & 49 & $22.0 \%$ & 38 & $21.5 \%$ & & \\
\hline & Absolute & 34 & $10.9 \%$ & 23 & $8.5 \%$ & 4 & $1.8 \%$ & 6 & $3.4 \%$ & & \\
\hline \multirow[t]{3}{*}{ ECOG, n. (\%) } & 0 & 198 & $63.5 \%$ & 190 & $70.1 \%$ & 152 & $68.2 \%$ & 139 & $78.5 \%$ & 0.002 & 0.12 \\
\hline & 1 & 89 & $28.5 \%$ & 67 & $24.7 \%$ & 59 & $26.5 \%$ & 29 & $16.4 \%$ & & \\
\hline & $2-3$ & 25 & $8.0 \%$ & 14 & $5.2 \%$ & 12 & $5.4 \%$ & 9 & $5.1 \%$ & & \\
\hline \multirow[t]{2}{*}{ Lesion site, n. (\%) } & Polar & 190 & $60.9 \%$ & 166 & $61.3 \%$ & 118 & $52.9 \%$ & 111 & $62.7 \%$ & 0.69 & 0.23 \\
\hline & Mediorenal & 122 & $39.1 \%$ & 105 & $38.7 \%$ & 105 & $47.1 \%$ & 66 & $37.3 \%$ & & \\
\hline \multirow{3}{*}{$\begin{array}{l}\text { Tumour growth } \\
\text { pattern, n. (\%) }\end{array}$} & $\geq 50 \%$ exo & 230 & $73.7 \%$ & 214 & $79.0 \%$ & 163 & $73.1 \%$ & 135 & $76.3 \%$ & 0.51 & 0.47 \\
\hline & $<50 \%$ exo & 75 & $24.0 \%$ & 51 & $18.8 \%$ & 52 & $23.3 \%$ & 36 & $20.3 \%$ & & \\
\hline & Entirely endo & 7 & $2.2 \%$ & 6 & $2.2 \%$ & 8 & $3.6 \%$ & 3.4 & $3.4 \%$ & & \\
\hline \multicolumn{2}{|c|}{ Clinical diameter, median (IQR) } & 3.0 & $2.0-4.0$ & 3.0 & $2.0-3.7$ & 3.2 & $2.5-4.3$ & 3.0 & $2.1-4.2$ & 0.04 & 0.001 \\
\hline \multirow[t]{3}{*}{ Clinical T, n. (\%) } & T1a & 253 & $81.1 \%$ & 229 & $84.5 \%$ & 165 & $74.0 \%$ & 127 & $71.8 \%$ & 0.07 & 0.002 \\
\hline & $\mathrm{T} 1 \mathrm{~b}$ & 57 & $18.3 \%$ & 35 & $12.9 \%$ & 53 & $23.8 \%$ & 46 & $26.0 \%$ & & \\
\hline & $\mathrm{T} 2$ & 2 & $0.6 \%$ & 7 & $2.6 \%$ & 5 & $2.2 \%$ & 4 & $2.3 \%$ & & \\
\hline \multirow[t]{2}{*}{ Volume centre, n. (\%) } & High & 194 & $62.2 \%$ & 202 & $74.5 \%$ & 186 & $83.4 \%$ & 134 & $75.7 \%$ & 0.002 & $<0.0001$ \\
\hline & Low & 118 & $37.8 \%$ & 69 & $25.5 \%$ & 37 & $16.6 \%$ & 43 & $24.3 \%$ & & \\
\hline
\end{tabular}


Table 2

Intraoperative data.

\begin{tabular}{|c|c|c|c|c|c|c|c|c|c|c|c|}
\hline \multicolumn{2}{|l|}{ RECORd1 } & \multicolumn{8}{|c|}{ Single year evaluation } & \multicolumn{2}{|l|}{$\mathrm{p}$} \\
\hline & & \multicolumn{2}{|l|}{2009} & \multicolumn{2}{|c|}{2010} & \multicolumn{2}{|l|}{2011} & \multicolumn{2}{|l|}{2012} & \multirow{2}{*}{$\frac{2009 \text { vs } 2012}{0.04}$} & \multirow{2}{*}{$\frac{2009 / 10 \text { vs } 2011 / 12}{0.75}$} \\
\hline \multirow[t]{2}{*}{ Technique, n. \% } & Enucleation & 101 & $32.4 \%$ & 132 & $48.7 \%$ & 90 & $40.4 \%$ & 74 & $41.8 \%$ & & \\
\hline & Enucleores/PN & 211 & $67.6 \%$ & 139 & $51.3 \%$ & 133 & $59.6 \%$ & 103 & $58.2 \%$ & & \\
\hline \multirow[t]{3}{*}{ Approach, n. $\%$} & Open & 217 & $69.6 \%$ & 168 & $62.0 \%$ & 110 & $49.3 \%$ & 68 & $38.4 \%$ & $<0.0001$ & $<0.0001$ \\
\hline & VLP & 95 & $30.4 \%$ & 103 & $38.0 \%$ & 59 & $26.5 \%$ & 45 & $25.4 \%$ & & \\
\hline & Robotic & 0 & $0.0 \%$ & 0 & $0.0 \%$ & 54 & $24.2 \%$ & 64 & $36.2 \%$ & & \\
\hline \multirow[t]{2}{*}{ Pedicle clamping, n $\%$} & Not clamped & 103 & $33.0 \%$ & 91 & $33.6 \%$ & 88 & $39.5 \%$ & 75 & $42.4 \%$ & 0.04 & 0.02 \\
\hline & Clamped & 209 & $67.0 \%$ & 180 & $66.4 \%$ & 135 & $60.5 \%$ & 102 & $57.6 \%$ & & \\
\hline \multicolumn{2}{|c|}{ Ischaemia time, median IQR } & 16 & $12-20$ & 17 & $13-21$ & 17 & $13-21$ & 16 & $12-20$ & 0.91 & 0.83 \\
\hline \multirow{2}{*}{$\begin{array}{c}\text { Emostatic material } \\
\text { used, } \mathrm{n} \%\end{array}$} & Yes & 261 & $83.7 \%$ & 250 & $92.3 \%$ & 215 & $96.4 \%$ & 172 & $97.2 \%$ & $<0.0001$ & $<0.0001$ \\
\hline & No & 51 & $16.3 \%$ & 21 & $7.7 \%$ & 8 & $3.6 \%$ & 5 & $2.8 \%$ & & \\
\hline \multicolumn{2}{|l|}{ EBL, median IQR } & 150 & $100-300$ & 150 & $100-250$ & 150 & $100-250$ & 200 & $100-300$ & 0.04 & 0.11 \\
\hline \multicolumn{2}{|c|}{ Operative time, median IQR } & 130 & $105-160$ & 130 & $100-180$ & 130 & $105-180$ & 140 & $115-170$ & 0.07 & 0.11 \\
\hline
\end{tabular}
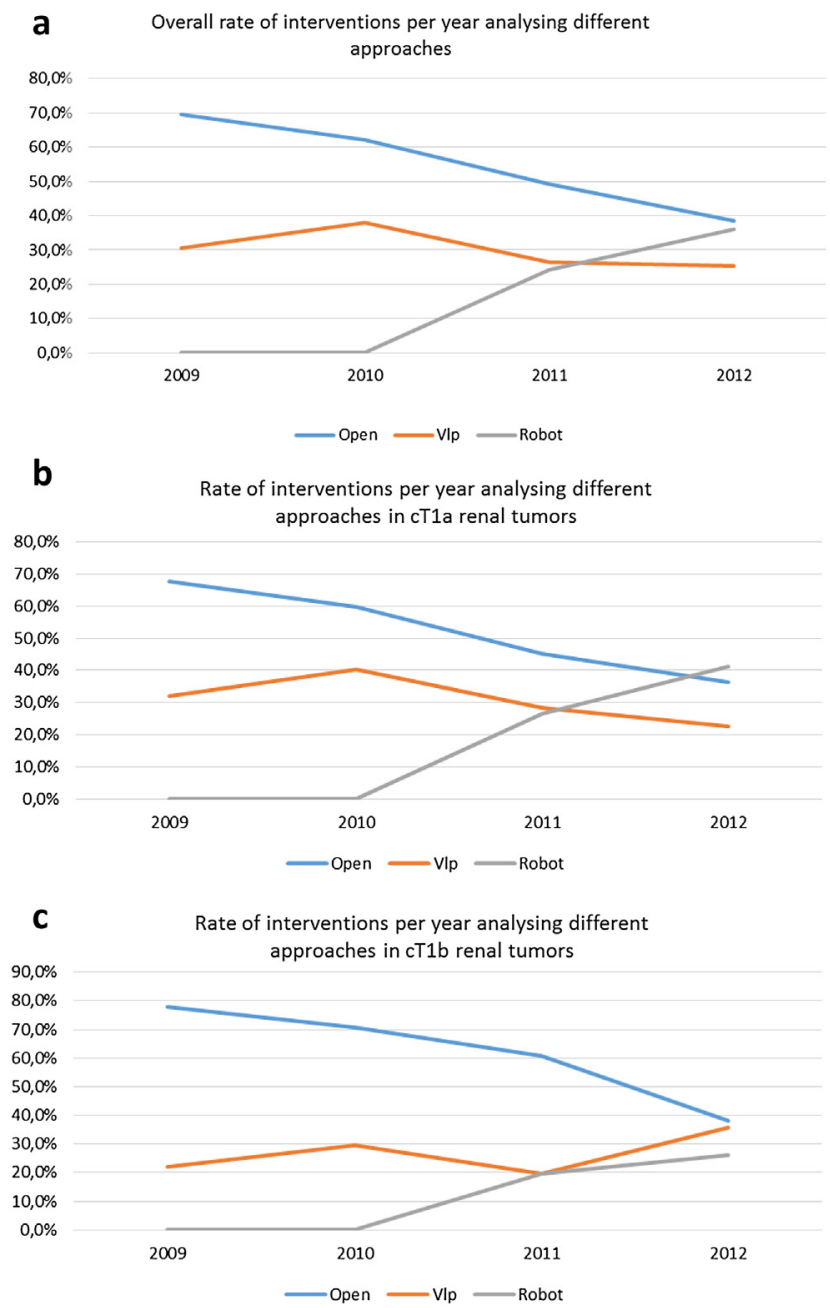

Figure 1. (a) Utilization rate of open, laparoscopic and robot-assisted partial nephrectomy over time. VLP = videolaparoscopic. (b) Utilization rate of open, laparoscopic and robot-assisted partial nephrectomy for cT1a renal tumours. (c) Utilization rate of open, laparoscopic and robotassisted partial nephrectomy for $\mathrm{cT} 1 \mathrm{~b}$ renal tumours. of 2009 to $37.7 \%$ in OPN, but dropped down to $25 \%$ in 2011. The rate of laparoscopic PN performed without hilar clamping increased from $42.1 \%$ in 2009 to $77.8 \%$ in 2011. Similar results have been observed for RAPN (from 24.1\% to $35.9 \%$ in the last two years). The use of at least one haemostatic agent was recorded in $91.3 \%$ of procedures (898/ 983), with a significantly higher utilization in the most recent surgical era $(p<0.001)$. Pathological data are reported in Table 3. Globally, no statistically significant differences among the surgical periods were found in terms of tumour's histological type and surgical margin status (Table 3). Patients undergoing NSS had slightly larger pathological diameter in the most recent era $(\mathrm{p}=0.02)$ and also the percentage of procedures for higher than pT1a RCC renal masses significantly increased $(\mathrm{p}<0.0001)$.

\section{Discussion}

The increasing utilization of non-invasive abdominal imaging (computed tomography, magnetic resonance imaging and ultrasonography) during the past 20 years has led to a significant growing number of incidentally detected small, asymptomatic, renal masses. ${ }^{9,10}$ In this scenario, renal cell carcinoma (RCC) has been going through a stage and size migration. ${ }^{11} \mathrm{~A}$ not negligible amount of these asymptomatic SRMs will prove to be benign after definitive pathological examination. ${ }^{12}$ Considering, above all, the functional benefits and the comparable oncological outcomes over RN offered by NSS, partial nephrectomy has been therefore more widely adopted among urological centres. ${ }^{13,14}$ In the present study, we evaluated the clinical, demographic, intraoperative and pathological data of those patients undergoing PN between 2009 and 2012 in 19 Italian Institutions. In this study, although the period considered is relatively short (4 years), asymptomatic patients were significantly higher in the second half of the evaluation period. Furthermore, patients of the more recent surgical era were significantly younger and healthier. Almost $80 \%$ of the procedures were performed in an elective setting, with a 
a

Overall rate of clamped and clampless procedure over the period considered.

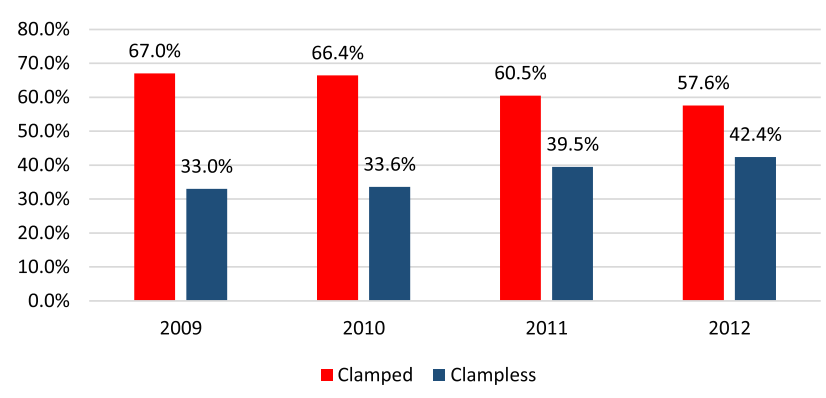

b

Clamped and clampless OPN procedure per year

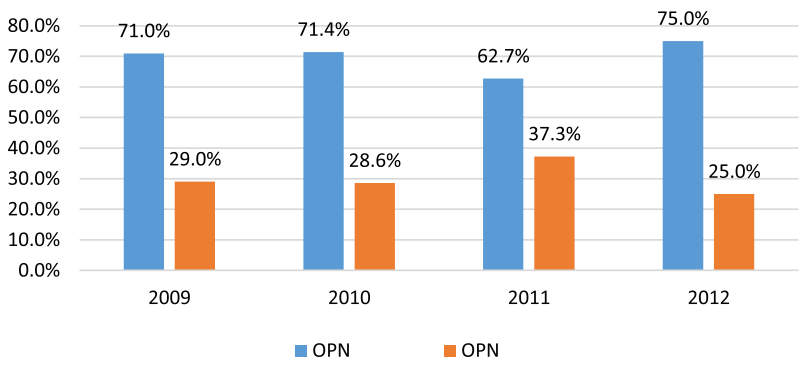

C

Clamped and clampless VPN procedure per year

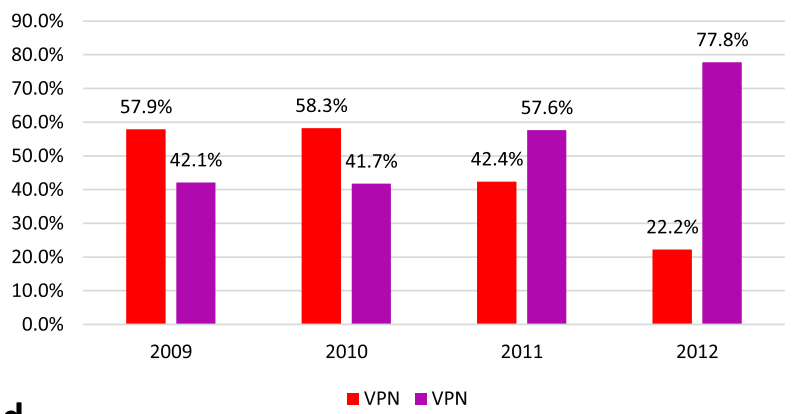

d

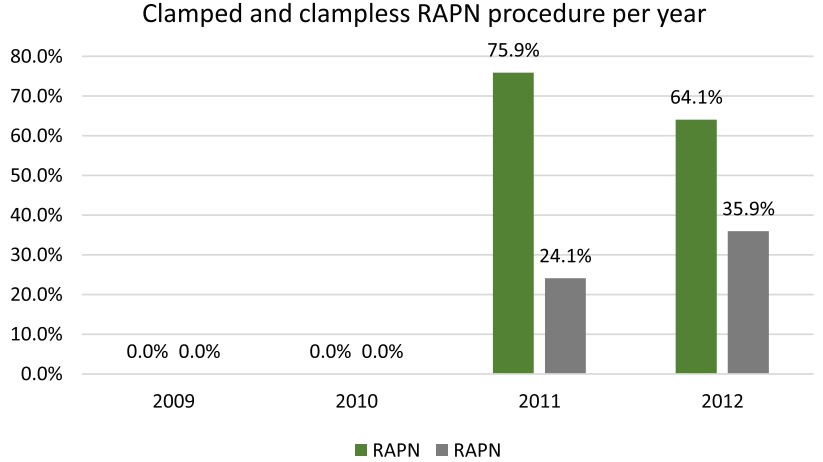

Figure 2. Clamped and clampless of overall (a), OPN (b), VPN (c) and RAPN procedure analysed over the period considered.

fairly significant constant trend of relative indication over time $(7.1 \%$ in 2009 vs $21.5 \%$ in 2012 , p < 0.0001). Notably, the vast majority of patients treated with elective $\mathrm{PN}$ showed an optimal performance status $(\mathrm{ECOG}=0$, $\mathrm{p}=0.002$ ). International Guidelines recommend to perform $\mathrm{PN}$ for $\mathrm{cT} 1 \mathrm{a}{ }^{2}$ Several studies have suggested that the indications for elective PN can be safely expanded to patients with larger (between 4 and $7 \mathrm{~cm}$ ) or more complex renal tumours, ${ }^{15-17}$ nevertheless with a slightly higher incidence of postoperative complications compared to NSS performed for cT1a tumours. ${ }^{18,19}$ According to the results of our study, a statistically significant increase in PN utilization rates for T1b RCC has been recorded over time (23-26\% in 2011/ 2012 vs $13-18 \%$ in 2009/2010, $\mathrm{p}=0.002$ ). The utilization rate of OPN decreased over time both for $\mathrm{cT} 1 \mathrm{a}$ and $\mathrm{cT} 1 \mathrm{~b}$ tumours remaining the standard and referent procedure in centres without advanced laparoscopic and robotic expertise or in case of more complex and challenging lesions (large tumours, with hilar location or involvement of the collecting system, Fig. 1). Conversely, LPN is a wellestablished and adopted procedure in high-volume Institutions with minimally invasive expertise. Robot-assisted approach has led to a reduction in the learning curve, offering more easy and reproducible surgical steps compared to the traditional laparoscopy, becoming a safe alternative to OPN and LPN in the treatment of renal tumours, for both cT1a and cT1b lesions. ${ }^{17,20-22}$ Despite the previous, historical recommendations to remove at least $1 \mathrm{~cm}$ of normal appearing renal parenchyma around the tumour in order to ensure negative margins, ${ }^{23}$ the current indications for NSS have been progressively changed. Indeed, according to the need for preservation of as much functioning healthy parenchyma as possible to minimize the loss of renal function, ${ }^{2,24}$ NSS has moved from maximal parenchymal resection to a minimal tissue removal. Simple enucleation (SE), defined as the blunt enucleation of the tumour along the inflammatory pseudocapsule surrounding healthy parenchyma, ${ }^{25}$ has been used with a slightly increasing trend over time ( $p=0.04$, Table 2$)$. An essential aspect of any partial nephrectomy is to provide a complete resection of the tumour, often in a bloodless field, within a limited warm ischaemia time (WIT). There is a large amount of evidences about the importance of reducing the WIT and the related risk of kidney injury and CKD. ${ }^{26}$ Thompson et al. showed that every minute of WIT was associated with a $6 \%$ increased risk of acute renal failure, $7 \%$ increased risk of acute-onset end stage renal disease and $4 \%$ increased risk of new-onset end stage renal disease. ${ }^{27}$ Several studies and meta-analyses demonstrated that RAPN could be safely performed with significantly lower WIT than LPN. ${ }^{28-30}$ In our series, the mean WIT was always within 20 min, with no significant differences in the surgical eras (Table 3). Overall, clampless procedures rate significantly increased from 33\% in 2009 to $42.4 \%$ in 2012 ( $\mathrm{p}=0.04$ ) (Table $3)$. This result shows a higher concern of surgeons to reduce the time of ischaemia and, whenever possible, to avoid pedicle clamping, and has been confirmed by a sub analysis that consider separately clampless PN rate for each approach. In LPN and RAPN this rate constantly increased over years, while OPN clampless rate constantly increased in the first three years and then it decreased in 2012. A possible explanation could be related to the case selection towards tumours of higher complexity in the OPN group 
Table 3

Pathological data.

\begin{tabular}{|c|c|c|c|c|c|c|c|c|c|c|c|}
\hline \multicolumn{2}{|l|}{ RECORd1 } & \multicolumn{8}{|c|}{ Single year evaluation } & \multicolumn{2}{|l|}{$\mathrm{p}$} \\
\hline & & 2009 & & 2010 & & 2011 & & 2012 & & 2009-2012 & $2009 / 10$ vs $2011 / 12$ \\
\hline \multirow[t]{2}{*}{ Tumour nature } & Benign & 68 & $21.8 \%$ & 51 & $18.8 \%$ & 36 & $16.1 \%$ & 28 & $15.8 \%$ & 0.50 & 0.63 \\
\hline & Malignant & 244 & $78.2 \%$ & 220 & $81.2 \%$ & 187 & $83.9 \%$ & 149 & $84.2 \%$ & & \\
\hline \multicolumn{2}{|c|}{ Pathological diameter, median IQR } & 3.0 & $2.1-4.0$ & 3.0 & $2.2-3.8$ & 3.2 & $2.3-4.0$ & 3.0 & $2.5-4.2$ & 0.10 & 0.02 \\
\hline \multirow{2}{*}{\multicolumn{2}{|c|}{ Surgical margins, n. $\%$}} & 233 & $95.5 \%$ & 212 & $96.4 \%$ & 175 & $93.6 \%$ & 141 & $95.3 \%$ & 0.81 & 0.58 \\
\hline & & 11 & $4.5 \%$ & 8 & $3.6 \%$ & 12 & $6.4 \%$ & 8 & $4.7 \%$ & & \\
\hline \multirow[t]{4}{*}{ Pathological T } & pT1a & 189 & $77.5 \%$ & 166 & $75.5 \%$ & 126 & $67.4 \%$ & 89 & $59.7 \%$ & $<0.0001$ & $<0.0001$ \\
\hline & pT1b & 46 & $18.9 \%$ & 31 & $14.1 \%$ & 36 & $19.3 \%$ & 44 & $29.5 \%$ & & \\
\hline & pT2 & 0 & $0.0 \%$ & 4 & $1.8 \%$ & 3 & $1.6 \%$ & 4 & $2.7 \%$ & & \\
\hline & pT3 & 9 & $3.6 \%$ & 19 & $8.6 \%$ & 22 & $11.7 \%$ & 12 & $8.1 \%$ & & \\
\hline
\end{tabular}

over years. The control of haemostasis represents a crucial step during PN. It depends on efficient retraction of small vessels, appropriate clot formation, and effective occlusion of all bleeding points with intraluminal clot or extraluminal compression with sutures, clips, or staples. ${ }^{31}$ Although several expected differences have been found among all tertiary care centres, tumour bed haemostasis has been preferably performed with interrupted and continuous sutures, while the utilization of hem-o-lok/titanium clips or argon laser represented less common techniques. Conversely, the utilization of haemostatic agents increased over time ( $\mathrm{p}<0.0001$, Table 2 ), with predominantly use of tissue sealants agent, particularly during LPN and RAPN although their efficacy to reduce the risk of postoperative bleeding has not been proved yet. ${ }^{32}$ When performing NSS for RCC, the complete removal of the tumour and the avoidance of positive surgical margins (PSMs) is of paramount importance, to reach optimal long-term oncological control. In the current literature, the overall incidence of PSMs after nephron-sparing surgery, when performed electively is quite low, ranging from $0 \%$ to $7 \%{ }^{33}$ and according to the surgical approach, the rate of PSMs is generally comparable between the different approaches. ${ }^{33}$ In our series, the overall PSMs rate is comparable to those reported in literature, with no significant differences in the surgical eras (Table 3). It must be noted that the findings reported in the present paper should be considered in the context of the study design. Our analysis represents only a limited investigation on our prospective multi-Institutional evaluation over a 4-year period. Clearly, data are not reflective of all urological centres and should not be generalized, thus not being applicable to other Centres with lowest surgical volume. The study lacks of any comparative intent between different PN approaches; analysis of surgical or medical complications, costs are beyond the scope of the dataset which has the main aim in describing the actual features of nephron-sparing surgery in Italy, with particular attention to significant trends that could be recorded during each year investigated and, though in absence of any comparison with RN, in supporting the role of PN as an established standard of care for $\mathrm{RCC}$.

\section{Conclusion}

Nephron-sparing surgery still remains the gold standard treatment for clinically localized RCC, whenever technically feasible. The utilization rate of NSS in high-volume Italian Centres is increasing over time, even in elective and more complex cases, with optimal results and safety profile. Robot-assisted partial nephrectomy is being much more adopted in the recent years compared to traditional laparoscopy. The rate of clampless procedures, regardless of the surgical approach, as well as the utilization of haemostatic agents at the end of the procedure, increased over time.

\section{Conflict of interest statement}

All authors have no conflicts of interest to declare.

\section{References}

1. Ferlay J, Soerjomataram I, Ervik M, et al. GLOBOCAN 2012 v1.0, cancer incidence and mortality worldwide: IARC CancerBase No. 11. [Internet]. Lyon, France: International Agency for Research on Cancer; 2013.

2. Patard JJ, Shvarts O, Lam JS, et al. Safety and efficacy of partial nephrectomy for all $\mathrm{T} 1$ tumors based on an international multicenter experience. J Urol 2004;171:2181.

3. Go AS, Chertow GM, Fan D, et al. Chronic kidney disease and the risk of death, cardiovascular events, and hospitalization. $N$ Engl J Med 2004;351:1296-305.

4. Ljungberg B, Bensalah K, Bex A, et al. Guidelines on renal cell carcinoma. In: EAU guidelines, edition presented at the 29th EAU Annual Congress, Stockholm, ISBN 978-90-79754-65-6; 2014.

5. Oken MM, Creech RH, Tormey DC, et al. Toxicity and response criteria of the Eastern Cooperative Oncology Group. Am J Clin Oncol 1982;5:649-55.

6. Patard JJ, Leray E, Cindolo L, et al. Multi-institutional validation of a symptom based classification for renal cell carcinoma. J Urol 2004; 172:858.

7. Minervini A, Ficarra V, Rocco F, et al. Simple enucleation is equivalent to traditional partial nephrectomy for renal cell carcinoma: results of a nonrandomized, retrospective, comparative study. J Urol 2011 May;185(5):1604-10.

8. Greene FL, Page DL, Fleming ID, et al. American Joint Committee on Cancer (AJCC) staging manual. 7th ed. Philadelphia: Springer; 2009. 
9. Hollingsworth JM, Miller DC, Daignault S, et al. Rising incidence of small renal masses: need to reassess treatment effect. J Natl Cancer Inst 2006;98:1331-4.

10. Concoran AT, Russo P, Lowrance WT, et al. A review of contemporary data on surgically resected renal masses-benign or malignant? Urology 2013 Apr;81(4):707-13.

11. Volpe A, Panzarella T, Rendon RA, et al. The natural history of incidentally detected small renal masses. Cancer 2004;100:738-45.

12. Welch HG, Black WC. Overdiagnosis in cancer. J Natl Cancer Inst 2010;102:605-13.

13. Zini L, Patard JJ, Capitanio U, et al. The use of partial nephrectomy in European tertiary care centers. Eur J Surg Oncol 2009 Jun;35(6): 636-42.

14. Capitanio U, Terrone C, Antonelli A, et al. Nephron-sparing techniques independently decrease the risk of cardiovascular events relative to radical nephrectomy in patients with a T1a-T1b renal mass and normal preoperative renal function. Eur Urol 2014 Oct 2. http://dx.doi.org/10.1016/j.eururo.2014.09.027 pii: S0302-2838(14) 00964-6.

15. Leibovich BC, Blute ML, Cheville JC, et al. Nephron sparing surgery for appropriately selected renal cell carcinoma between 4 and $7 \mathrm{~cm}$ results in outcome similar to radical nephrectomy. J Urol 2004;171: 1066-70.

16. Antonelli A, Ficarra V, Bertini R, et al. Elective partial nephrectomy is equivalent to radical nephrectomy in patients with clinical T1 renal cell carcinoma: results of a retrospective, comparative, multiinstitutional study. BJU Int 2012 Apr;109(7):1013-8.

17. Borghesi M, Schiavina R, Gan M, et al. Expanding utilization of robotic partial nephrectomy for clinical T1b and complex T1a renal masses. World J Urol 2013 Jun;31(3):499-504.

18. Patard J-J, Pantuck AJ, Crepel M, et al. Morbidity and clinical outcome of nephron-sparing surgery in relation to tumor size and indication. Eur Urol 2007;52:148-54.

19. Fardoun T, Chaste D, Oger E, et al. Predictive factors of hemorrhagic complications after partial nephrectomy. Eur J Surg Oncol 2014 Jan; 40(1):85-9.

20. Mottrie A, Borghesi M, Ficarra V. Is traditional laparoscopy the real competitor of robot-assisted partial nephrectomy? Eur Urol 2012 Dec;62(6):1034-6.

21. Minervini A, Siena G, Carini M. Robotic-assisted partial nephrectomy: the next gold standard for the treatment of intracapsular renal tumors. Expert Rev Anticancer Ther 2011;11(12):1779-82.
22. Ficarra V, Minervini A, Antonelli A, et al. A multicentre matched-pair analysis comparing robot-assisted versus open partial nephrectomy. BJU Int 2014 Jun;113(6):936-41.

23. Uzzo RG, Novick AC. Nephron sparing surgery for renal tumors: indications, techniques and outcomes. J Urol 2001 Jul;166(1):6-18.

24. Kaushik D, Kim SP, Childs MA, et al. Overall survival and development of stage IV chronic kidney disease in patients undergoing partial and radical nephrectomy for benign renal tumors. Eur Urol 2013 Oct; 64(4):600-6.

25. Longo N, Minervini A, Antonelli A, et al. Simple enucleation versus standard partial nephrectomy for clinical T1 renal masses: perioperative outcomes based on a matched-pair comparison of 396 patients (RECORd project). Eur J Surg Oncol 2014 Jun;40(6):762-8.

26. Kim SP, Thompson RH, Boorjian SA, et al. Comparative effectiveness for survival and renal function of partial and radical nephrectomy for localized renal tumors: a systematic review and meta-analysis. $J$ Urol 2012;188(1):51-7.

27. Thompson RH, Lane BR, Lohse CM. Every minute counts when the renal hylum is clamped during partial nephrectomy. Eur Urol 2010; 58:340-5.

28. Aboumarzouk OM, Stein RJ, Eyraud R, et al. Robotic versus laparoscopic partial nephrectomy: a systematic review and meta-analysis. Eur Urol 2012;62:1023-33.

29. Zhang X, Shen Z, Zhong S, et al. Comparison of peri-operative outcomes of robot-assisted vs laparoscopic partial nephrectomy: a meta-analysis. BJU Int 2013 Dec;112(8):1133-42.

30. Masson-Lecomte A, Bensalah K, Seringe E, et al. A prospective comparison of surgical and pathological outcomes obtained after robotassisted or pure laparoscopic partial nephrectomy in moderate to complex renal tumours: results from a French multicentre collaborative study. BJU Int $2013 \mathrm{Feb} ; 111(2): 256-63$.

31. Ramanathan R, Leveillee RJ. A review of methods for hemostasis and renorraphy after laparoscopic and robot-assisted partial nephrectomy. Curr Urol Rep 2010;11:208-20.

32. Antonelli A, Minervini A, Mari A, et al. TriMatch comparison of the efficacy of FloSeal versus TachoSil versus no hemostatic agents for partial nephrectomy: results from a large multicenter dataset. Int $J$ Urol 2014 Aug 19. http://dx.doi.org/10.1111/iju.12603.

33. Borghesi M, Brunocilla E, Schiavina R, Martorana G. Positive surgical margins after nephron-sparing surgery for renal cell carcinoma: incidence, clinical impact, and management. Clin Genitourin Cancer 2013;11:5-9. 